\title{
Analitik Hiyerarşi Prosesi Tekniği İle Kayak Merkezlerinin Tercih Edilme Yönelimlerinin Değerlendirilmesi ${ }^{1}$
}

\author{
Serap YURTTAKALAN² ve Cavit YEŞILYURT ${ }^{3}$
}

\section{$\ddot{\mathrm{O} z}$}

Bu çalışmanın amacı Türkiye'deki kayak merkezi seçiminde müşterilerin bakış açısıyla kayak merkezi yönelimlerini Analitik Hiyerarşi Prosesi tekniği ile değerlendirmektir. Uzman kişiler tarafindan beyin firtınası yöntemiyle belirlenen 7 kriter ile 6 kayak merkezi değerlendirilmiştir. Değerlendirmelerde matematiksel işlemlerde kolaylık sağlaması amacıyla Super Decisions paket programı kullanılmıştır. Değerlendirme sonucunda en etkili kriter reklam ve tavsiyeler olurken, en az etkili kriter ise mevsim uzunluğu olarak belirlenmiştir. Uludağ Kayak Merkezi belirlenen alternatifler arasından en çok tercih edilen alternatif olmuştur.

Anabtar Kelimeler: Kayak merkezi, Çok kriterli karar verme, Analitik hiyerarşi prosesi (AHP)

\section{Evaluation of Preferred Directions of Ski Centers via Analytic Hierarchy Process Technique}

\section{Abstract:}

The purpose of this study is to evaluate the ski resort trends in Turkey with the Analytic Hierarchy Process technique from the customers' perspective in ski resort selection. Seven criteria brainstormed by the experts were used in the assessment of six ski centers. In practice, the Super Decisions package program is used in order to facilitate the mathematical operations. According to the results of the research the most effective criteria are the advertisement and recommendations, while the least effective criterion is the season length. Uludag Ski Center has become the most preferred alternative among the alternatives determined.

Key Words: Ski centers, Multiple criteria decision making, Analytic hierarchy process (AHP)

\section{Atıf İçin / Please Cite As:}

Yurttakalan, S. ve Yeşilyurt, C. (2020). Analitik hiyerarşi prosesi tekniği ile kayak merkezlerinin tercih edilme yönelimlerinin değerlendirilmesi. Manas Sosyal Arastırmalar Dergisi, 9(2), 973-984.

Geliş Tarihi / Received Date: 28.02.2019

Kabul Tarihi / Accepted Date: 04.03.2020

\footnotetext{
${ }^{1}$ Bu çalışmada Cavit Yeşilyurt’un Danışmanlığında Serap Yurttakalan’ın “Analitik Hiyerarşi Prosesi Tekniği İle Kayak Merkezlerinin Tercih Edilme Yönelimlerinin Değerlendirilmesi” isimli Yüksek Lisans Tezinden Yararlanılmıstır.

${ }^{2}$ Serap Yurttakalan, serapyurttakalan@gmail.com

ORCID: 0000-0001-8393-5861

3 Doç. Dr. - Atatürk Üniversitesi İktisadi ve İdari Bilimler Fakültesi, cavityesilyurt@atauni.edu.tr ORCID: 0000-0001-9814-4085
} 


\section{Giriş}

Günümüz insanının kapalı mekânlarda fazla zaman geçirmesi ve uzun süre masa başında çalışılması kişilerde belli aralıklarla mola verme zorunluğu doğurmuştur. Bu durum tatil kavramını biraz daha önemli hale getirmiştir. Özellikle refah düzeyinin yükselmesi ile yaz aylarında oluşan tatil algısı kış ayları içinde oluşmuştur. Kış tatilleri için en çok tercih edilen yerlerin başında kayak merkezleri gelmektedir.

İnsanların tatillerinden optimum faydayı sağlama istekleri tatillerini geçirecekleri merkezler arasından en uygununu seçme sorununu ortaya çıkarmaktadır. Pek çok alanda olduğu gibi kayak merkezlerinin de en uygununun seçilmesi birden çok kriter içereceğinden seçimin çok kriterli karar verme teknikleri kullanılarak yapılmasını zorunlu kilmıştır. Birden fazla ve birbiri ile çelişen seçeneklerin varllğı hem kişisel hem de şirket kararları için kafa karışıklığına neden olmaktadır. Bu doğrultuda geliştirilen Çok Kriterli Karar Verme teknikleri hem karar verme sürecini kolaylaştırmakta hem de nitel ve nicel değerlerin birlikte kullanmasına imkân vermektedir.

Çok Kriterli Karar Verme tekniklerinden bir tanesi de Analitik Hiyerarşi Prosesi (AHP) tekniğidir. Hem nitel hem de nicel değerleri dikkate alarak en iyi alternatifin seçilmesine yardımcı olmaktadır. Analitik Hiyerarşi Prosesi tekniği kullanım kolaylığı, basitlik ve kolay yorumlanabilme gibi özellikleri nedeniyle geniş bir kullanım alanına sahiptir. Bu nedenle çalışmada kayak merkezlerinin tercih edilme yönelimleri Analitik Hiyerarşi Prosesi tekniği ile belirlenmeye çalışılmıştır.

\section{Literatür Taraması}

Eleren (2006) dericilik sektöründe faaliyet gösteren işletmeler için kuruluş yeri seçimi problemi çözümünde AHP tekniğini kullanmıştır. Belirlenen altı kriter (pazara yakınlık, hammaddeye yakınlık, ulaşım imkanları, devlet teşvikleri, işgücü, altyapı) ve altı alternatif şehir (Ankara, Uşak, Afyon, İstanbul, Antalya, İzmir) arasında değerlendirme yapılmıştır. Yapılan değerlendirmeler sonucunda kuruluş yeri seçimi için belirlenen alternatifler arasından ilk üç sırayı İstanbul, İzmir, Uşak şehirleri almıştır.

Tüzemen ve Özdağoğlu (2007) Dokuz Eylül Üniversitesi Sosyal Bilimler Enstitüsü işletme doktora programı öğrencilerinin eş seçimi konusunu AHP tekniği ile değerlendirmişlerdir. Yapılan çalışmada 3 ana kriter (Kişisel Özellikler, Çevresel Özellikler, İkili İlişki) ve 11 alt kriter (Fiziksel Özellikler, Aile Yapısı, Karakteristik Özellikler, Yaşam Felsefesi - Dünya Görüşü, Sosyo - Kültürel Düzey, Eğitim Düzeyi, Sosyal Statü, Maddi Durum, Aşk, Sevgi, Mantık) kullanılarak belirlenen kriterlerin önem sıraları değerlendirilmiştir. Çalışmada doktora öğrencilerinin eş seçiminde ilk sırada sevgi faktörü, ikinci sırada aile ve üçüncü sırada karakter faktörünü dikkate aldıkları ortaya çıkmışır. Sevgi ile birlikte bir takım toplumsal beklentileri karşılayan kişisel özelliklerinde önemli olduğu sonucuna varılmıştır.

Dündar (2008) üniversite öğrencilerinin seçmeli ders seçiminde alabilecekleri derslerin belirlenmesi için AHP tekniğini kullanmıştır. Belirtilen örneklem üzerinde yapılan çalısmada dersin öğretim elamanlarının özellikleri, dersin ismi ve içeriğ̈i, dersle ilgili öğrencilerden elde edilen bilgiler olmak üzere 3 kriter ve 3 alternatif ders ile değerlendirme yapılmıştır. Değerlendirme sonucunda ilk sırada dersi verecek öğretim elemanının özellikleri, ikinci sırada dersle ilgili öğrencilerden elde edilen bilgiler, üçüncü sırada dersin adı ve içeriğinin dikkate alındığı sonucuna ulaşılmıştır.

Dündar ve Ecer (2008) üniversite öğrencilerinin GSM operatör tercihleri üzerine yaptıkları çalışmada AHP tekniğini kullanmışlardır. Belirlenen beş kriter (konuşma ücreti, kapsama alanı, öğrencinin ailesinin GSM operatörü aboneliği, hat ücreti, hizmet kalitesi) ve üç alternatif ile operatörlerin tercih edilme sıraları belirlenmiştir.

Doğan ve Gencan (2013) Kapadokya Bölgesinde seyahat acentelerinin bakış açısı ile yaptıkları çalışmayı AHP tekniği ile değerlendirmişlerdir. Değerlendirmede 5 kriter (fiyat, hizmet kalitesi, tavsiye edilme oranı, otelin konumu ve müşteri güvenliği) ve 4 alternatif otel kullanılarak oteller arasından en uygun otel seçilmiştir.

Ömürbek, Üstündağ ve Helvacioğlu (2014) hafif ticari araç seçimini AHP temelli PROMETHEE teknikleri ile yapmışlardır. Belirlenen 10 kriter (fiyat, yakıt, maksimum hız, beygir gücü, performans, yük hacmi, dayanıklilık, marka, servis imkanı, ikinci el fiyatlar) ve 9 alternatif kullanılarak sıralama yapılmıştır. Kriter ağırlıkları AHP tekniği ile belirlendikten sonra en uygun araç seçilmiştir.

Günaydın (2008) Türkiye'nin en büyük 100 perakende şirketi arasından seçilen 4 teknoloji şirketini uzman görüşleri ile belirlenen 8 kriter (reklam, güvenlik, mağaza sayısı, ürün çeşitliliği, fiyat, hizmet kalitesi, 
ödeme koşulları, satış sonrası destek) ile değerlendirmiştir. Yapılan anket çalışmaları doğrultusunda katılımcılar en çok tercih edilen teknolojik marketi belirlemiştir.

\section{Yöntem}

Bu çalışmada kayak merkezlerinin tercih edilme yönelimleri incelenmiştir. Çalışmada yöntem olarak çok kriterli karar verme yöntemlerinden biri olan AHP yöntemi kullanılmıstır.

Analitik Hiyerarşi Prosesi (AHP) Myers ve Albert tarafından 1968 yllında oluşturulmuş daha sonrasında Thomas Lorie Saaty tarafindan geliștirilerek Çok Nitelikli Karar Verme problemlerinde kullanılmıştır (Yaralıŏglu, 1999, s. 981-997). Karar verilirken salt bilgi yerine insanın yargılarının da hesaba katılması kararın etkinliğini artırabilmektedir. Çünkü her insanın olaylara farklı yaklaşımı, farklı kriterlerin oluşumuna ve oluşan seçenekler için de farklı değerlendirmelere neden olmaktadır (Adıg̈̈zel vd., 2009, s. 21). AHP tekniği bireyleri bir kalıp içine sokarak belli bir karar için yönlendirme yapmaz. Bunun yerine kendi inisiyatifi ile karar vermesine olanak sağlar (Günaydın, 2008, s. 21). AHP tekniği karar vericilerin karar verirken önceden var olan deneyim, öngörü, sezgi, kullandıkları bilgiyi çeşitlendirerek çözüm yoluna farklı şekillerde ulaşmalarını sağlar. Böylece verilen kararın hem objektif hem de subjektif değerlendirme yapmalarına olanak sağlayarak, karmaşık çözümleri basitleştirir (Dyer, 1990, s. 249-258). AHP tekniği nitel ve nicel değişkenlerin karşılaştırılmasına imkân sunan, bu değişkenleri sıralamaya firsat veren, çok değişken içeren ve karmaşık problemlerin çözümde kullanılan bir yöntem olarak tanımlanmaktadır. Kriterlerin ve alt kriterlerin kıyaslamaları yapılarak üstünlükleri belirlenip en iyi alternatifi belirleme işlemi için kullanılır. Yöntemin basit ve anlaşılır olması da işletmelerde kullanılmasını kolaylaştırmaktadır (Özyörük ve Özcan, 2008, s. 1-2).

AHP'nin tanımı sıralı "Analitik", "Hiyerarşi”" ve "Proses" kelimelerinde gizlenmiştir ve bu kelimeler AHP'nin en genel tanımı için yol göstermektedir. "Analitik" kelime anlamı olarak "çözümle" anlamını taşımaktadır (www.tdk.gov.tr). Yani matematiksel olarak "mubakeme etmek" olarak da ifade edilebilir. AHP yöntemi; birçok alternatifin ve kriterlerin varlığında, karar vericinin olası ikili karşılaştırmaları değerlendirmesi ve birçok işlemden sonra alternatiflerin 0-1 Aralığında değer alıp, toplamı 1 olacak şekilde sayısallaştırıp, tek boyuta indirgeyerek karar verilme işleminin basitleştirilmesidir (Özçalıc1, 2017, s. 45). "Hiyerarşı" ise kelime anlamı olarak "basamak, derece düzeni, aşama sirası "olarak tanımlanmaktadır (www.tdk.gov.tr). AHP yönteminde problemi bir düzen içinde biçimlendirmek kolay bir çözümlemenin başlangıcıdır. "Proses" kelimesinin Türkçe karşılığ ise süreç anlamını taşımaktadır. Yani olay ve olguların bir düzen içinde sıralanması esnasında gecen süreçtir. AHP yönteminde diğer yöntemlerde olduğu gibi karar verici belli adımlardan sonra ve belli bir düzen içinde süreçten tasarruf ederek kararını vermeyi hedeflemektedir.

\section{AHP'nin Adımları}

Özden AHP'nin adımlarını sistem analizi çerçevesinde aşağıdaki şekilde göstermiştir (Özden, 2008, s. 302):

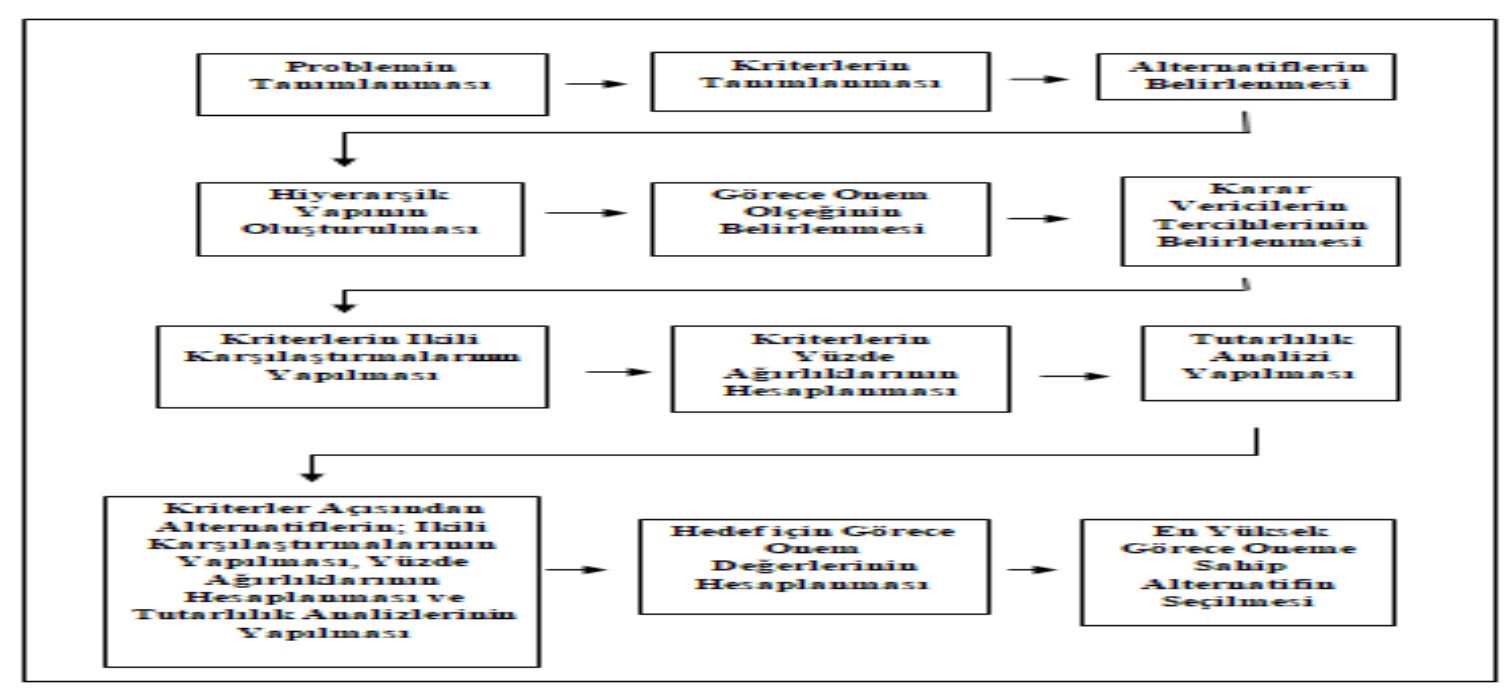

Şekil 1. AHP'nin Așamalar 
Timor (2011, s. 29) AHP’nin adımları aşağıdaki şekilde özetlemiştir:

1. Hedef listesinin belirlenmesi.

2. Hedeflerin oluşturulabilmesi için kriterlerin sıralanması.

3. Belirlenen kriterler için alternatiflerin oluşturulması.

4. Hiyerarşik modelin kurulması.

\section{Problemin Tanımlanması}

AHP'nin ilk adımı olarak problem tanımlanması yapılır. Bunun nedeni karar vericinin hangi amaca ulaşmak istediğini belirleyebilmesidir (Özden, 2008, s. 302).

\section{Kriterlerin Tanımlanması}

AHP probleminde dikkate alınması gereken kriterler saptanır. Sadece ana kriterler kullanılabileceği gibi hem alt hem de ana kriterleri de kullanmak mümkündür. Kriterler oluşturulurken uzman kişilerin görüşlerinden yararlanılabilir. Fakat alt kriterlerin fazlalı̆̆ı problemi çözmeyi zorlaştırmaktadır (Özçalıcı, 2017, s. 46; Koçak, 2003, s. 70).

\section{Alternatiflerin Belirlenmesi}

Alternatifler de kriterler gibi araştırmacı taraf veya uzman görüşleri alınarak saptanmaktadır. Alternatifler belirlenirken benzer veya yakın alternatiflerin oluşturulmasına dikkat edilmelidir. Yakın olmayan alternatifler analiz sonuçlarının hatalı çıkmasına sebep olmaktadır (Özçalıcı, 2017, s. 46).

\section{Hiyerarşik Yapının Oluşturulması}

Hiyerarşik yapının kurulması klasik problem çözme tekniklerinde " model kurma” gibi düşünülmektedir. Fakat hiyerarşik yapı kişiden kişiye farklılık gösterebilmektedir ve hiyerarşik yapının en önemli özelliği ise her bir adımdaki elamanlar ve bu elamanların arasındaki etkileşimdir (Tanyaş ve Fığlalı, 1999, s. 673). Hiyerarşide en alt basamakta alternatif olmak üzere sirasıyla üst basamaklarda kriterler ve amaç bulunmaktadır. Hiyerarşik yapı oluşturulurken amacın belirlenmesi öncelik olmalıdır. Bunun nedeni ise kriter ve alternatiflerin amaca göre şekillendirilip oluşturulmasıdır (Önder ve Önder, 2014, s. 26).

Karar problemleri için hiyerarşik yapı kullanılması karar verici için avantajlar oluşturmaktadır. Bunlar Saaty tarafindan açıklanmışır (Günaydın, 2008, s. 33).

\section{Görece Önem Ölçeğinin Belirlenmesi}

AHP'de ulaşılmak istenen amaç, daha sonrasında kriterler ve amaca uygun alternatifler belirlendikten sonra ikili karşılaştırma matrisi oluşturulacaktır. İkili karşılaştırma matrisi oluşturulurken Saaty'e ait olan ölçek kullanılmaktadır (Keleş, 2014, s. 62). Saaty'nin oluşturduğu ölçeğin hem iki öğe arasındaki ayrıştırma yeteneği ile örtüştüğü hem de kullanım kolaylığ̣ sağladığı düşünülmektedir (Çınar, 2004, s. 117). Bu ölçek dışında farklı ölçeklerde kullanmak mümkündür. Fakat literatürde en sık kullanılan ölçek Saaty ölçeğidir (Özçalıc1, 2017, s. 47). Bu çalışmada Saaty ölçeğinden yararlanılacaktır.

Tablo 1. Saaty Ölçeği (Görece Önem Ölçĕgi)

\begin{tabular}{clc}
\hline Önem Ölçeği & Kavramsal Tanımlama & Açıklama \\
\hline 1 & Eşit & Ikki seçenek eşit derecede önemli \\
\hline 2 & Zayıf & Bir seçenek diğerine göre çok az önemli \\
\hline 3 & Orta & Bir seçenek diğerine göre kuvvetli derecede önemli \\
\hline 4 & Orta+ & Bir seçenek diğerine göre çok önemli \\
\hline 5 & Kuvvetli & \\
\hline 7 & Kuvvetli+ & Bir seçenek diğerine tercih edilmekte
\end{tabular}

Kaynak: Saaty (2008, s. 86)

Ölçek 1-9 arasında değer almaktadır. Aralığın ne olacağı hakkında kesin bir bilgi olmamakla birlikte ölçeğin 1-5 arasında değer alması hassasiyet kaybına; geniş tutulması ise karar vericilerin zorlanmasına neden olmaktadır (Özçalıcı, 2017, s. 47). Sözel ifadelerin sayısal değerler ile ifade edildiği ölçekte, ikili karşılaştırma yapılırken karar verici fikrini en iyi yansıtan ifadeyi tercih eder. Örneğin karar verici A ve B alternatiflerini karşılaştıryyorsa bu alternatiflerin birbirine göre ne kadar önemli olduğu sorusu yöneltilir. A alternatifi B alternatifine göre eşit derecede önemli ise sayısal olarak 1, biraz daha fazla önemli ise 
3,kuvvetli derecede önemli ise 5 , çok kuvvetli derecede önemli ise 7 , aşır1 güçlü derecede önemli ise 9 değeri işaretlenir. 2, 4, 6, 8 değerleri ise ara değerler olarak nitelendirilir. Bu değerler çoğunlukla karar vericinin iki değer arasında kararsız kaldığı durumlarda kullanılmaktadır (Günaydın, 2008, s. 35).

\section{Kayak Merkezlerinin AHP İle Değerlendirilmesi}

Türkiye'nin dağlık bir ülke olması ve bol kar yağışı alması nedeniyle kayak merkezi sayısı her geçen gün artmaktadır. Bu çalışmada Türkiye'deki en popüler 18 kayak merkezi ve 20 kriter incelenmiş, hem sektörden hem de üniversitelerin konuyla ilgili uzmanları ile yüz yüze görüşülmüsstür. Kayak merkezlerinin seçiminin değerlendirilmesinde 38 kişiye anketler uygulanmıştır. Katılımcılar 25-45 yaş aralığında, en az lise mezunu, aylık 3.000 TL ve üzeri maddi gelire sahip ve belirtilen kayak merkezlerinin en az birinde kayak tecrübesi olan kişilerdir. Bunlar arasında karşılaştırma yapmak üzere 6 kayak merkezi ve 7 kriter seçilmiştir. Belirlenen kayak merkezleri ve kriterler aşağıdaki şekildedir:

- Uludağ Kayak Merkezi (Bursa)

- Kartalkaya Kayak Merkezi (Bolu)

- Erciyes Kayak Merkezi (Kayseri)

- Sarıkamıs Kayak Merkezi (Kars)

- Palandöken Kayak Merkezi (Erzurum)

- Ilgaz Kayak Merkezi (Kastamonu)

Belirlenen kriterler ise aşağıdaki şekildedir:

- Mevsim uzunluğu

- Keşfedilmemiş doğal güzellikler

- Kar kalitesi

- Ulaşım kolaylı̆̆

- Alternatiflerine göre uygun fiyatlı olma

- Kayak yapilabilen gün sayıs1

- Reklam ve tavsiyeler

Mevsim Uzunluğu: Kayak sporunun yapılabildiği kış mevsiminin uzunluğudur. Örneğin Türkiye'de doğuya doğru yükselti arttığı için karın yerde kalma süresi dolayısı ile de kış mevsiminin süresi artmaktadır.

Keşfedilmemiş Doğal Güzellikler: Henüz keşfedilmeyen ya da az bilinen yerler olarak ifade edilmektedir. Türkiye hem tarihi hem de doğal güzellikleri içinde barındıran bir ülke konumundadır.

Kar Kalitesi: En iyi kar kalitesi karın toz gibi ince ve kuru olması şeklinde ifade edilmektedir (www.akşam.com.tr). Özellikle kayak veya kış sporu ile ilgilenen kişilerin pist ezildikten sonra kara yapışmadan, slalom yapılmasında kolaylık sağladığı bilinmektedir.

Ulaşım Kolaylığı: Bir yerden bir yere gidiş gelişte erişilebilen rahatlık olarak ifade edilebilir. Özellikle mesafelerin kısa olması, trafik olmaması ulaşımı kolaylaştıran etkenlerdendir.

Alternatiflerine Göre Uygun Fiyatlı Olması: Kayak merkezlerinde bulunan otel vb. hizmetlerin fiyat algisını ifade eder. Belirli sezonlarda oluşturulan indirim kampanyaları ile yeni bir fiyat algisı oluşturulur. Oluşturulan fiyat algıları ile diğer kayak merkezlerinin müşteri üzerindeki etkisi değerlendirilir.

Kayak Yapılabilen Gün Sayısı: Sisli, puslu, rüzgârlı, firtınalı ve fazla kar yağışının olduğu durumlarda kayak sporunun yapılması oldukça zordur. Bu durum kayak sporu severlerini zorlayan bir durumdur.

Reklam ve Tavsiyeler: Kayak merkezlerinin görsel basındaki tanıtımı ve insanların birbiri ile iletişimlerindeki tavsiyeleri ifade eder. Reklam ve tavsiyelerin kayak merkezlerine müşteriyi çekme etkisi değerlendirilmiştir.

\section{Hiyerarşik Yapının Kurulması}

Problemin çözümünde ilk olarak AHP içinde gerekli olan hiyerarşik yapı oluşturulur. Hiyerarşik yapı Şekil 2'de gösterilmiştir.

1. Amaç 
2. Kriterler (Mevsim uzunluğu, Keşfedilmemiş doğal güzellikler, Kar kalitesi, Ulaşım kolaylı̆̆ı, Alternatiflerine göre uygun fiyatlı olma, Kayak yapılabilen gün sayısı, Reklam ve tavsiyeler)

3. Alternatifler (Uludağ Kayak Merkezi (Bursa), Kartalkaya Kayak Merkezi (Bolu), Erciyes Kayak Merkezi (Kayseri), Sarıkamış Kayak Merkezi (Kars), Palandöken Kayak Merkezi (Erzurum), Ilgaz Kayak Merkezi (Kastamonu))

Hiyerarşik yapı oluşturulurken kısaltmalardan yararlanılmıştır. Kriterler ve alternatifler aşağıdaki şekilde kısaltılmıştır.

\section{Kriterler:}

- Mevsim uzunluğu=M.UZ

- Keşfedilmemiş doğal güzellikler=K.D.G

- Kar kalitesi=K.K

- Ulaşım kolaylı̆̆ $=\mathrm{U} . \mathrm{K}$

- Alternatiflerine göre uygun fiyatlı olma=A.U.F.O

- Kayak yapilabilen gün sayısı=K.Y.G.S

- Reklam ve tavsiyeler=R. ve T.

\section{Alternatifler:}

- $\quad$ Uludağ Kayak Merkezi =U.K.M

- Kartalkaya Kayak Merkezi=K.K.M

- Erciyes Kayak Merkezi=E.K.M

- Sarıkamış Kayak Merkezi=S.K.M

- Palandöken Kayak Merkezi=P.K.M

- Ilgaz Kayak Merkezi=I.K.M

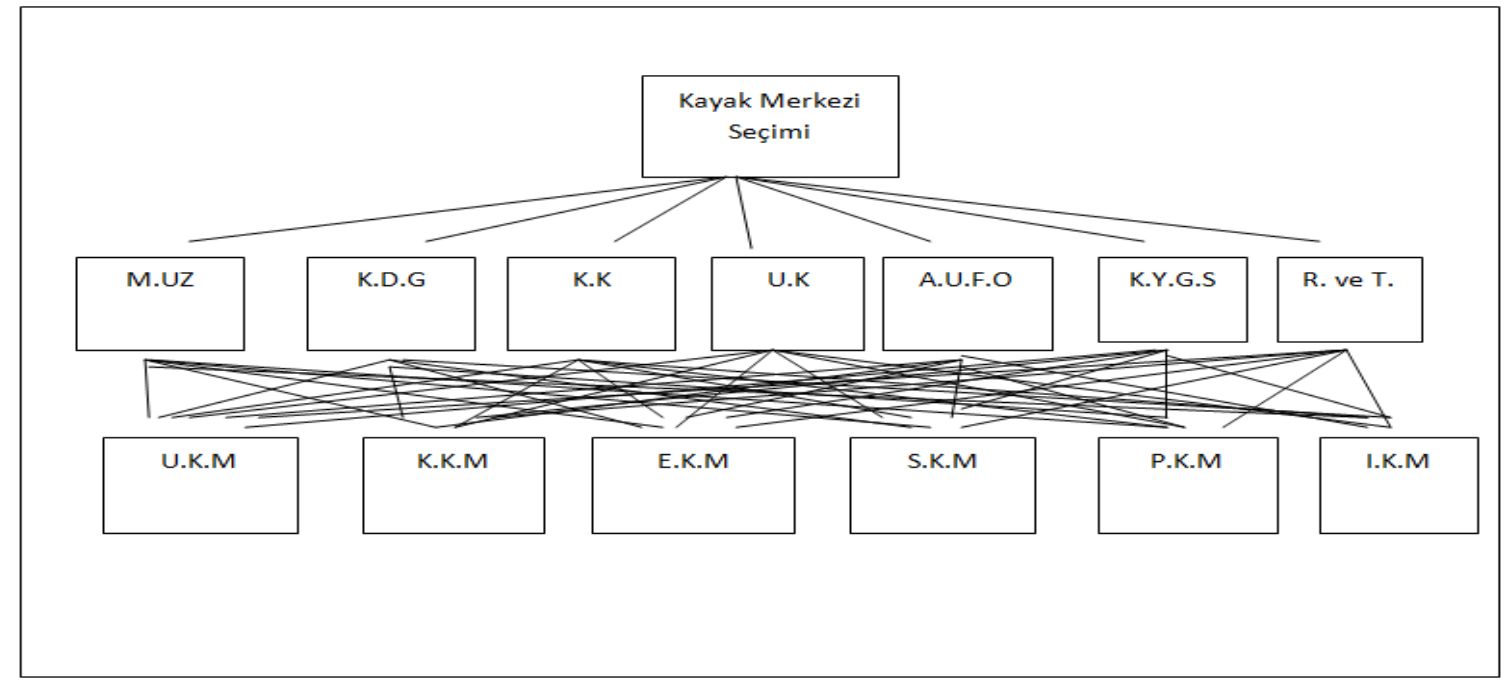

Şekil 2. Problemin Hijerarşik Yapısı

Birbiri ile bağlanan amaç, kriterler ve alternatifler ile hiyerarşik yap1 oluşturulmuştur. Hiyerarşik yapı problemin daha iyi algılanmasını sağlamaktadır ve en üstte amaç sonra kriterler ve en altta ise alternatifler basamaklandırılarak hiyerarşik yapı kurulmuştur. Daha sonrasında ikili karşılaştırma matrisi için anketler sonucunda oluşturulan veriler girilecektir.

\section{İkili Karşılaştırma Matrislerinin Oluşturulması}

Kriterlerin ikili karşılaştırma matrisleri ankete katılan kişilerden elde edilen değerlendirmeler ile oluşturulmuştur. Ankete sektörden seçilen 38 uzman kişi katılmış, katılan kişiler bir grup olarak düşünülüp; değerlendirmelerin geometrik ortalaması alınmıştır. Anket sonuçlarına göre oluşturulan matrisler Tablo 1 ve Tablo 2'de gösterilmiştir. 
Tablo 2. Kriterlerin Birbiri ile Karşılaştırılması

\begin{tabular}{cccccccc}
\hline Kriterler & A.U.F.O. & K.D.G. & K.K. & K.Y.G.S & M.UZ. & R. ve T. & U.K. \\
\hline A.U.F.O & $\mathbf{1 , 0 0}$ & $\mathbf{2 , 0 0}$ & $\mathbf{2 , 0 0}$ & $\mathbf{3 , 0 0}$ & $\mathbf{4 , 0 0}$ & $\mathbf{0 , 2 0}$ & $\mathbf{3 , 0 0}$ \\
K.D.G & 0,50 & 1,00 & 0,25 & 0,50 & 4,00 & 0,25 & 3,00 \\
K.K & 0,50 & 4,00 & 1,00 & 2,00 & 3,00 & 0,25 & 2,00 \\
K.Y.G.S & 0,33 & 2,00 & 0,5 & 1,00 & 4,00 & 0,20 & 1,00 \\
M.UZ & 0,25 & 0,25 & 0,33 & 0,25 & 1,00 & 0,20 & 0,50 \\
R.veT. & 5,00 & 4,00 & 4,00 & 5,00 & 5,00 & 1,00 & 6,00 \\
U.K. & 0,33 & 0,33 & 0,50 & 2,00 & 2,00 & 0,17 & 1,00 \\
\hline
\end{tabular}

Tablo 2'de kayak merkezi seçiminde alternatiflerine göre uygun fiyatlı olma, keşfedilmemiş doğal güzellikler, kar kalitesi, kayak yapılabilen gün sayısı, mevsim uzunluğu, reklam ve tavsiyeler, ulaşım kolaylığ1 kriterleri birbiri ile karşılaştırılmıştır. Örneğin; alternatiflerine göre uygun fiyatlı olma kriteri keşfedilmemiş doğal güzellikler kriterinden 2 kat, kar kalitesi kriterinden 2 kat, kayak yapılabilen gün sayısı kriterinde 3 kat, mevsim uzunluğu kriterinden 4 kat, reklam ve tavsiyeler kriterinden $1 / 5$ kat ve ulaşım kolaylı̆̆1 kriterinden 3 kat daha önemlidir. Matris üzerine bulanan köşegen değerler, aynı kriterler birbiri ile karşılaştırıldığı için bir değerini almıştır. Değerlendirmelere göre reklam ve tavsiyeler kriteri diğer kriterlerden farklı oranlarda daha önemli iken, mevsim uzunluğu kriteri diğer kriterlerden farklı oranlarda daha az önemlidir.

Tablo 3. Kriterlerin Alternatiflere Göre Karşılaștonlması

\begin{tabular}{|c|c|c|c|c|c|c|c|c|c|c|c|c|c|}
\hline $\begin{array}{c}\text { A.U. } \\
\text { O }\end{array}$ & $\begin{array}{c}\text { E.K. } \\
\text { M }\end{array}$ & $\begin{array}{c}\text { I.K. } \\
\text { M }\end{array}$ & $\begin{array}{c}\text { K.K. } \\
\mathbf{M}\end{array}$ & $\begin{array}{c}\text { P.K. } \\
\text { M }\end{array}$ & $\begin{array}{c}\text { S.K. } \\
\text { M }\end{array}$ & $\begin{array}{c}\text { U.K. } \\
\text { M }\end{array}$ & $\begin{array}{c}\text { K.D. } \\
\text { G }\end{array}$ & $\begin{array}{c}\text { E.K. } \\
\text { M }\end{array}$ & $\begin{array}{c}\text { I.K. } \\
\text { M }\end{array}$ & $\begin{array}{c}\text { K.K. } \\
\text { M }\end{array}$ & $\begin{array}{c}\text { P.K. } \\
\text { M }\end{array}$ & $\begin{array}{c}\text { S.K. } \\
\text { M }\end{array}$ & $\begin{array}{c}\text { U.K. } \\
\mathbf{M}\end{array}$ \\
\hline $\begin{array}{c}\text { E.K. } \\
\text { M }\end{array}$ & ,00 & 3,00 & 4,00 & 2,00 & 0,50 & 5,00 & E.K.M & 1,00 & 0,20 & 0,50 & 0,50 & 0,25 & 2,00 \\
\hline $\begin{array}{c}\text { I.K. } \\
\text { M }\end{array}$ & 0,33 & 1,00 & 2,00 & 2,00 & 0,50 & 3,00 & I.K.M & 5,00 & 1,00 & 4,00 & 3,00 & 4,00 & 5,99 \\
\hline $\begin{array}{c}\text { K.K. } \\
\text { M }\end{array}$ & 0,25 & 0,50 & 1,00 & 0,33 & 0,25 & 2,00 & K.K.M & 2,00 & 0,25 & 1,00 & 0,50 & 0,20 & 2,00 \\
\hline $\begin{array}{c}\text { P.K. } \\
\text { M }\end{array}$ & 0,50 & 0,50 & 3,00 & 1,00 & 0,50 & 4,00 & P.K.M & 2,00 & 0,33 & 2,00 & 1,00 & 0,33 & 2,00 \\
\hline $\begin{array}{c}\text { S.K. } \\
\text { M }\end{array}$ & 2,00 & 2,00 & 4,00 & 2,00 & 1,00 & 5,00 & S.K.M & 4,00 & 0,25 & 5,00 & 3,00 & 1,00 & 4,00 \\
\hline $\begin{array}{c}\text { U.K. } \\
\text { M }\end{array}$ & 0,20 & 0,33 & 0,50 & 0,25 & 0,20 & 1,00 & U.K.M & 0,50 & 0,17 & 0,50 & 0,50 & 0,25 & 1,00 \\
\hline K.K. & $\begin{array}{c}\text { E.K. } \\
\text { M }\end{array}$ & $\begin{array}{c}\text { I.K. } \\
\text { M }\end{array}$ & $\begin{array}{c}\text { K.K. } \\
\mathbf{M}\end{array}$ & $\begin{array}{c}\text { P.K. } \\
\text { M }\end{array}$ & $\begin{array}{c}\text { S.K. } \\
\text { M }\end{array}$ & $\begin{array}{c}\text { U.K. } \\
\mathbf{M}\end{array}$ & $\begin{array}{c}\text { K.Y.G. } \\
\text { S }\end{array}$ & $\begin{array}{c}\text { E.K. } \\
\mathbf{M}\end{array}$ & $\begin{array}{c}\text { I.K. } \\
\text { M }\end{array}$ & $\begin{array}{c}\text { K.K. } \\
\mathbf{M}\end{array}$ & $\begin{array}{c}\text { P.K. } \\
\text { M }\end{array}$ & $\begin{array}{c}\text { S.K. } \\
\text { M }\end{array}$ & $\begin{array}{c}\text { U.K. } \\
\mathbf{M}\end{array}$ \\
\hline $\begin{array}{c}\text { E.K. } \\
\text { M }\end{array}$ & 1,00 & 0,50 & 0,33 & 0,25 & 0,20 & 0,33 & E.K.M & 1,00 & 1,00 & 0,50 & 0,33 & 0,33 & 0,50 \\
\hline $\begin{array}{c}\text { I.K. } \\
\text { M }\end{array}$ & 2,00 & 1,00 & 0,50 & 0,25 & 0,20 & 0,50 & I.K.M & 1,00 & 1,00 & 0,50 & 0,25 & 0,33 & 0,50 \\
\hline $\begin{array}{c}\text { K.K. } \\
\text { M }\end{array}$ & 3,00 & 2,00 & 1,00 & 0,33 & 0,25 & 0,50 & K.K.M & 2,00 & 2,00 & 1,00 & 0,33 & 0,25 & 0,50 \\
\hline $\begin{array}{c}\text { P.K. } \\
\text { M }\end{array}$ & 4,00 & 4,00 & 3,00 & 1,00 & 0,50 & 2,00 & P.K.M & 3,00 & 4,00 & 3,00 & 1,00 & 0,50 & 2,00 \\
\hline $\begin{array}{c}\text { S.K. } \\
\text { M }\end{array}$ & 5,00 & 5,00 & 4,00 & 2,00 & 1,00 & 4,00 & S.K.M & 3,00 & 3,00 & 4,00 & 2,00 & 1,00 & 2,00 \\
\hline $\begin{array}{c}\text { U.K. } \\
\text { M }\end{array}$ & 3,00 & 2,00 & 2,00 & 0,50 & 0,25 & 1,00 & U.K.M & 2,00 & 2,00 & 2,00 & 0,50 & 0,50 & 1,00 \\
\hline $\begin{array}{c}\text { M.U } \\
\text { Z } \\
\end{array}$ & $\begin{array}{c}\text { E.K. } \\
\text { M }\end{array}$ & $\begin{array}{c}\text { I.K. } \\
\text { M }\end{array}$ & $\begin{array}{c}\text { K.K. } \\
\mathbf{M}\end{array}$ & $\begin{array}{c}\text { P.K. } \\
\text { M }\end{array}$ & $\begin{array}{c}\text { S.K. } \\
\text { M }\end{array}$ & $\begin{array}{c}\text { U.K. } \\
\mathbf{M}\end{array}$ & $\begin{array}{c}\text { R.ve } \\
\text { T. }\end{array}$ & $\begin{array}{c}\text { E.K. } \\
\mathbf{M}\end{array}$ & $\begin{array}{c}\text { I.K. } \\
\text { M }\end{array}$ & $\begin{array}{c}\text { K.K. } \\
\mathbf{M}\end{array}$ & $\begin{array}{c}\text { P.K. } \\
\text { M }\end{array}$ & $\begin{array}{c}\text { S.K. } \\
\text { M }\end{array}$ & $\begin{array}{c}\text { U.K. } \\
\mathbf{M}\end{array}$ \\
\hline $\begin{array}{c}\text { E.K. } \\
\text { M }\end{array}$ & 1,00 & 3,00 & 2,00 & 0,25 & 0,50 & 2,00 & E.K.M & 1,00 & 0,25 & 0,25 & 0,50 & 2,00 & 0,20 \\
\hline $\begin{array}{c}\text { I.K. } \\
\text { M }\end{array}$ & 0,33 & 1,00 & 2,00 & 0,33 & 0,50 & 2,00 & I.K.M & 4,00 & 1,00 & 0,33 & 2,00 & 3,00 & 0,25 \\
\hline $\begin{array}{c}\text { K.K. } \\
\text { M }\end{array}$ & 0,50 & 0,50 & 1,00 & 0,25 & 1,00 & 3,00 & 4,00 & & 3,00 & 1,00 & 3,00 & 4,00 & 0,33 \\
\hline $\begin{array}{c}\text { P.K. } \\
\text { M }\end{array}$ & 4,00 & 3,00 & 4,00 & 1,00 & 3,00 & 4,00 & 2,00 & & 0,50 & 0,33 & 1,00 & 2,00 & 0,33 \\
\hline $\begin{array}{c}\text { S.K. } \\
\text { M }\end{array}$ & 2,00 & 2,00 & 1,00 & 0,33 & 1,00 & 3,00 & S.K.M & 0,50 & 0,33 & 0,25 & 0,50 & 1,00 & 0,33 \\
\hline U.K. & 0,50 & 0,50 & 0,33 & 0,25 & 0,33 & 1,00 & U.K.M & 5,00 & 0,25 & 3,00 & 3,00 & 3,00 & 1,00 \\
\hline
\end{tabular}




\begin{tabular}{|c|c|c|c|c|c|c|}
\hline \multicolumn{7}{|l|}{$\mathrm{M}$} \\
\hline U.K. & $\begin{array}{c}\text { E.K. } \\
\mathbf{M}\end{array}$ & $\begin{array}{l}\text { I.K. } \\
\text { M }\end{array}$ & $\begin{array}{c}\text { K.K. } \\
\mathbf{M}\end{array}$ & $\begin{array}{c}\text { P.K. } \\
\text { M }\end{array}$ & $\begin{array}{c}\text { S.K. } \\
\text { M }\end{array}$ & $\begin{array}{c}\text { U.K. } \\
\mathbf{M}\end{array}$ \\
\hline $\begin{array}{c}\text { E.K. } \\
\text { M }\end{array}$ & 1,00 & 3,00 & 4,00 & 0,50 & 4,00 & 5,00 \\
\hline $\begin{array}{c}\text { I.K. } \\
\text { M }\end{array}$ & 0,33 & 1,00 & 2,00 & 0,25 & 0,50 & 2,00 \\
\hline $\begin{array}{c}\text { K.K. } \\
\text { M }\end{array}$ & 0,25 & 0,50 & 1,00 & 0,33 & 0,50 & 2,00 \\
\hline $\begin{array}{c}\text { P.K. } \\
\text { M }\end{array}$ & 2,00 & 4,00 & 3,00 & 1,00 & 4,00 & 5,00 \\
\hline $\begin{array}{c}\text { S.K. } \\
\text { M }\end{array}$ & 0,25 & 2,00 & 2,00 & 0,25 & 1,00 & 2,00 \\
\hline $\begin{array}{c}\text { U.K. } \\
\text { M }\end{array}$ & 0,20 & 0,50 & 0,50 & 0,20 & 0,50 & 1,00 \\
\hline
\end{tabular}

Tablo 3'te her bir kriter alternatifler açısından karşılaștırılmıștır. Örneğin; ulaşım kolaylığı alternatifi açısından Erciyes Kayak Merkezi, Ilgaz Kayak Merkezine göre 3 kat, Kartalkaya Kayak Merkezine göre 4 kat, Palandöken Kayak Merkezine göre 1/2 kat, Sarıkamış Kayak Merkezine göre 4 kat, Uludağ Kayak Merkezine göre 5 kat önemlidir. Karşılaştırma matrisleri oluşturulduktan sonra matrislerin değerlendirilmesi yapılmıştır.

\section{Değerlendirme ve Bulguların Elde Edilmesi}

Anketlerden elde edilen veriler matrislere dönüştürülüp analizler yapılmıstır. Hiyerarşide bulunan öğeler için öncelikler matrisi, özvektör ve tutarllık oranları hesaplanmıştır. Hesaplamalar Super Decisions programı ile yapılmıştır. Super Decisions Çok Kriterli Karar Verme problemlerindeki AHP ve ANP tekniklerinin çözümlemelerinde kullanılan ve Saaty'nin de desteklediği bir programdır. Problemi çözebilmek için programa amaç, kriter ve alternatif girişleri yapılarak ilişkilendirmeler yapılır. Aşağıda Super Decisions programında oluşturulan hiyerarşik yapı taslağı oluşturulmuştur. Amaç, kriter ve alternatifler birbirleri ile ve tek tek ilişkileri tanımlamak için bağlanmıştır.

AHP yöntemi ile analiz edilen kayak merkezi seçim probleminde alternatif sıralama aşağıdaki şekildedir.

Tablo 4. Kayak Merkęlerinin Alternatif Siralaması

\begin{tabular}{lc}
\hline Kayak Merkezi Seçim Probleminde Alternatif Sıralaması & Ağırlıklar \\
\hline Uludă̆ Kayak Merkezi & 0.21 \\
Sarıkamı̧̋ Kayak Merkezi & 0.19 \\
Palandöken Kayak Merkezi & 0.16 \\
Kartalkaya Kayak Merkezi & 0.15 \\
Ilgaz Kayak Merkezi & 0.15 \\
Erciyes Kayak Merkezi & 0.11 \\
\hline
\end{tabular}

Karar vericiler tarafindan Uludağ Kayak Merkezi ilk sırada tercih edilen kayak merkezi iken, ikinci sırada Sarıkamış Kayak Merkezi ve üçüncü sırada Palandöken Kayak Merkezi tercih edilen kayak merkezleri olmuştur. Palandöken kayak merkezini sırasıyla; Kartalkaya Kayak Merkezi, Ilgaz Kayak Merkezi ve Erciyes Kayak Merkezi izlemiştir.

\section{Sonuç ve Öneriler}

Günümüz dünyasında insanların kapalı mekânlarda fazla zaman geçirmesi ve uzun süre masa başında çalışılması kişileri belli zamanlarda mola vermeye zorlamaktadır. Bu durum tatil isteğini doğurmaktadır. Özellikle refah düzeyinin yükselmesi ile yaz aylarında oluşan tatil alg1sı kış ayları içinde oluşmuştur. Kış tatilleri için en çok tercih edilen yerlerin başında kayak merkezleri gelmektedir. Bu çalı̧̧ada Çok Kriterli Karar Verme yöntemlerinden biri olan AHP tekniği kullanılmıştır. Çalışmada 38 kişiye anket uygulanmış, elde edilen sonuçların geometrik otalamaları alınarak çözüme ulaşılmıştır. Uygulamada Super Decisions programı kullanılarak nihai sonuç elde edilmiştir.

Mevsim uzunluğu, keşfedilmemiş doğal güzellikler, kar kalitesi, ulaşım kolayllğı, alternatiflerine göre uygun fiyatlı olma, kayak yapilabilen gün sayısı, reklam ve tavsiyeler kriterleri altında Uludağ Kayak Merkezi (Bursa), Kartalkaya Kayak Merkezi (Bolu), Erciyes Kayak Merkezi (Kayseri), Sarıkamıs Kayak Merkezi (Kars), Palandöken Kayak Merkezi (Erzurum), Ilgaz Kayak Merkezi (Kastamonu) arasindan değerlendirmeler yapılmıştır. Değerlendirmeler sonucunda kriter ağırlıkları büyükten küçüğe; Reklam ve 
Tavsiyeler, Alternatiflerine Göre Uygun Fiyatlı Olma, Kar Kalitesi, Kayak Yapılabilen Gün Sayısı, Keşfedilmemiş Doğal Güzellikler, Ulaşım Kolaylığı, Mevsim Uzunluğu şeklinde sıralanmıştır.

Yapılan değerlendirmeler sonucunda alternatifler için kriterlerin karşılaştırmaları tutarlı olmuş ve aşağıdaki sonuçlar elde edilmiştir:

Alternatiflerine göre uygun fiyath olma kriteri için ilk tercih edilen kayak merkezi Sarrkamış Kayak Merkezi, ikinci tercih edilen kayak merkezi Erciyes Kayak Merkezi ve üçüncü tercih edilen kayak merkezi Ilgaz Kayak Merkezi olmuştur. Ilgaz Kayak Merkezini sırasıyla Palandöken Kayak Merkezi, Kartalkaya Kayak Merkezi, Uludağ Kayak Merkezi izlemiştir.

Keşfedilmemiş doğal güzellikler kriteri açısından ilk tercih edilen kayak merkezi Ilgaz Kayak Merkezi olmuştur. Ilgaz Kayak Merkezini sırasıyla Sarıkamış Kayak Merkezi, Palandöken Kayak Merkezi, Kartalkaya Kayak Merkezi, Erciyes Kayak Merkezi, Uludağ Kayak Merkezi izlemiştir.

Kar kalitesi kriteri açısından ilk sırada tercih edilen kayak merkezi Sarıkamış Kayak Merkezi olmuştur. Sarıkamış Kayak Merkezini sırasıyla Palandöken Kayak Merkezi, Uludağ Kayak Merkezi, Kartalkaya Kayak Merkezi, Ilgaz Kayak Merkezi, Erciyes Kayak Merkezi izlemiştir.

Kayak yapılabilen gün sayısı kriteri açısından ilk tercih edilen kayak merkezi Sarıkamış Kayak Merkezi olmuştur. Sarıkamış Kayak Merkezini sırasıyla Palandöken Kayak Merkezi, Uludağ Kayak Merkezi, Kartalkaya Kayak Merkezi, Erciyes Kayak Merkezi, Ilgaz Kayak Merkezi izlemiştir.

Mevsim uzunluğu kriteri açısından ilk sırada tercih edilen kayak merkezi Palandöken Kayak Merkezi olmuştur. Palandöken Kayak Merkezini sırasıyla Sarıkamış Kayak Merkezi, Erciyes Kayak Merkezi, Ilgaz Kayak Merkezi, Kartalkaya Kayak Merkezi, Uludağ Kayak Merkezi izlemiştir.

Reklam ve Tavsiyeler kriteri açısından ilk tercih edilen kayak merkezi Uludağ Kayak Merkezi olmuştur. Uludağ Kayak Merkezini sırasıyla Kartalkaya Kayak Merkezi, Ilgaz Kayak Merkezi, Palandöken Kayak Merkezi, Erciyes Kayak Merkezi, Sarıkamış Kayak Merkezi izlemiştir.

Ulaşım Kolaylığı kriteri açısından ilk tercih edilen kayak merkezi Palandöken Kayak Merkezi olmuştur. Palandöken kayak merkezini sırasıyla Erciyes Kayak Merkezi, Sarıkamış Kayak Merkezi, Ilgaz Kayak Merkezi, Kartalkaya Kayak Merkezi, Uludağ Kayak Merkezi izlemiştir.

Karşılaştırmaların tümü yapıldıktan sonra AHP tekniğine göre kayak merkezi seçim probleminin nihai sonuçları ve sonuçların ağırlıklara göre sıralaması aşağıdaki gibidir:

- Uludağ Kayak Merkezi (0.21)

- Sarıkamış Kayak Merkezi (0.19)

- Palandöken Kayak Merkezi (0.16)

- Kartalkaya Kayak Merkezi (0.15)

- Ilgaz Kayak Merkezi (0.15)

- Erciyes Kayak Merkezi (0.11)

Benzer çalışmaların sonuç ve değerlendirmeleri için ise; Toy, Eymirli ve Karapınar (2010) çalışmalarında kayak sezon aralığını Palandöken Kayak Merkezi için 150 gün, Erciyes Kayak Merkezi için 150 gün, Uludağ Kayak Merkezi için 120 gün, Kartalkaya Kayak Merkezi için 120 gün ve Sartkamış Kayak Merkezi için 120 gün olarak belirtmişlerdir. Aydın (2007) çalışmasında dünyada sadece Alplerde olan toz kristal karın ülkemizde sadece Sarıkamış Kayak Merkezinde olduğunu belirtmiştir. Toy, Eymirli ve Karapınar (2010) çalışmalarında Palandöken Kayak Merkezinin kent merkezine uzaklığını 4 km, Erciyes Kayak Merkezinin kent merkezine uzaklığın 25 km, Uludağ Kayak Merkezinin kent merkezine uzakllğını 36 km, Kartalkaya Kayak Merkezinin kent merkezine uzaklı̆̆ını 40 km, Sarıkamış Kayak Merkezinin kent merkezine uzaklığın $55 \mathrm{~km}$ uzaklıkta olduğunu belirtmiştir.

\section{Kaynakça}

Adıgüzel, O., Çetintürk, İ. ve Er, O. (2009). Konaklama işletmelerinde olan müşteri tercihinin AHP yöntemi ile belirlenmesi. Süleyman Demirel Üniversitesi Viąyon Dergisi, 1(1), 17-35.

Aydın, A. D. (2007). Sarıkamış'ın kış sporları turizmi potansiyeli açısından değerlendirilmesi. Süleyman Demirel Üniversitesi Sosyal Bilimler Enstitüsü Dergisi, 2(6), 203-209.

Çınar, Y. (2004). Cok nitelikli karar verme ve bankalarn mali performanslarmm değerlendirilmesi örneği (Yüksek Lisans Tezi). Ankara Üniversitesi Sosyal Bilimler Enstitüsü, Ankara 
Doğan N. O. ve Gencan S. (2013). Seyahat acentesi yöneticilerinin bakış açısıyla en uygun otel seçimi: Analitik hiyerarşi prosesi (AHP) uygulaması. Erciyes Üniversitesi İktisadi ve İdari Bilimler Fakültesi Dergisi, 41, 69-88.

Dündar, S. (2008). Ders seçiminde analitik hiyerarşi proses uygulaması. Süleyman Demirel Üniversitesi İktisadi ve İdari Bilimler Fakültesi Dergisi, 13(2), 217-226.

Dündar, S. ve Ecer, F. (2008). Öğrencilerin GSM operatörü tercihini analitik hiyerarşi süreci yöntemiyle belirlenmesi. Celal Bayar Üniversitesi İ.̇.B.F. Yönetim ve Ekonomi, 15(1), 195-205.

Dyer, J. S. (1990). Remaks on the analytic hierarchy process. Manegement Science, 36, 249-258.

Eleren, A. (2006). Kuruluş yeri seçiminin analitik hiyerarşi süreci yöntemi ile belirlenmesi: Deri sektörü örneği. Atatürk Üniversitesi İktisadi ve İdari Bilimler Dergisi, 20(2), 405-416.

Evren, S. (2016). Türkiye'de kış turiz̧mi destinasyonlarmın rekabeţi konumlandirması (Yayınlanmamış Doktora Tezi). Anadolu Üniversitesi Sosyal Bilimler Enstitüsü, Eskişehir.

Günaydın, N. (2008). Analitik hiyerarşi prosesi ve bir uygulama (Yayınlanmamış Yüksek Lisans Tezi). Yıldız Teknik Üniversitesi Fen Bilimleri Enstitüsü, İstanbul

Kar Kalitesi. https://www.aksam.com.tr/ekonomi/turkiyenin-kar-kalitesi-baska- yerde-yok/haber- 3696035 May1s 2018

Keleş, M. K. (2014). Işsletmelerin teknokent sę̧iminde biyerarşik Electre yönteminin kullanım ve Ankara bölgesinde bir uygulama (Yayınlanmamış Doktora Tezi). Süleyman Demirel Üniversitesi Sosyal Bilimler Enstitüsü, Isparta

Koçak, A. (2003). Yazılım seçiminde analitik hiyerarşi yöntemi yaklaşımı ve bir uygulama. Ege Akademik Bakış Dergisi, 3(1), 67-77.

Ömürbek, N., Üstündağ, S. ve Helvacioğlu, Ö. C. (2013). Kuruluş yeri seçiminde analitik hiyerarşi süreci (AHP) kullanımı: Isparta bölgesinde bir uygulama. Yönetim Bilimleri Dergisi, 11(21), 101-116.

Önder, E. (2014). Analitik ağ süreci. İçinde B. F Yıldırım ve E. Önder (Edt.) Issletmeciler, mühendisler ve yöneticiler için operasyonel, yönetsel ve stratejik problemlerin çözünde çok kriterli karar verme yöntemleri (ss. 75-113) Bursa: Dora Yayinc1lik.

Önder, G. ve Önder, E. (2014). Analitik hiyerarşi süreci. İçinde B. F Yıldırım ve E. Önder (Edt.) İsletmeciler, mühendisler ve yöneticiler için operasyonel, yönetsel ve stratejik problemlerin çözünde çok kriterli karar verme yöntemleri (ss. 2164). Bursa: Dora Yayincilik.

Özçalıcı, M. (2017). Matlab ile çok kriterli karar verme teknikleri. Ankara: Nobel Akademik Yayıncılık.

Özden, Ü. (2008). Analitik hiyerarşi yöntemi ile okul seçimi. Marmara Üniversitesi İIBF Dergisi, 24(1), 299-320.

Özyörük, B. ve Özcan, E. C. (2008). Analitik hiyerarşi sürecinin tedarikçi seçiminde uygulanması: Otomotiv sektöründe bir uygulama. Süleyman Demirel ïniversitesi İ̈BF Dergisi, 13(1), 133-144.

Saaty, T. L. (2008). Decision making with the analytic hierarchy process. International Journal Services Sciences, 1(1), 8398.

Super Decisions, http://www.superdecisions.com/ 12 Mart 2018

Tanyaş, M. ve Fığlalı, A. (1999). Performans değerlendirme için yeni bir yöntem. Hava Harp Okulu 2000'li Yullarda Uzay, Havaculke ve Savunma Teknolojilerinin Öncelikler Sempozyumu Bildiri Kitabı (ss. 657-684). Ankara: Hava Harp Okulu Yayini.

Timor, M. (2010). Yöneylem araşttrması. İstanbul: Türkmen Kitabevi.

Timor, M. (2011). Analitik hiyerarşi prosesi. İstanbul: Türkmen Kitabevi.

Toy, S., Eymirli, E. B. ve Karapınar, M. (2010). Erzurum Korakh Bölgesi Kış Turiz̨m Merkezi Raporu. Erzurum: Kuzeydoğu Anadolu Kalkınma Ajans1, Turizm Raporları No: 2.

Tüzemen, A. ve Özdağoğlu, A. (2007). Doktora öğrencilerinin eş seçiminde önem verdikleri kriterlerin analitik hiyerarşi sureci yöntemi ile belirlenmesi. Atatürk Üniversitesi İktisadi ve İdari Bilimler Dergisi, 21(1), 215-232.

Türk Dil Kurumu Hiyerarşi Kelime Anlamı, http:/tdk.gov.tr,10 Şubat 2018

Türk Dil Kurumu, Analitik Kelime Anlamı, http://tdk.gov.tr 10 Şubat 2018

Türk Dil Kurumu, Karar Verme Kelime Anlamı, http://www.tdk.gov.tr,12 Aralık 2017

Türk Dil Kurumu, Risk Kelime Anlamı, http://tdk.gov.tr,19 Aralık 2017

Yaralığlu, K. (1999). Analitik hiyerarşi modeli ile genel seçim sonuçlarının öngörülmesi. 4. Ulusal Ekonometri ve İstatistik Sempozyити (ss. 981-997). Antalya.

\section{EXTENTED ABSTRACT}

Turkey's being a mountainous country ski center and the number is increasing due to receive plenty of snow every day. In this study, 6 ski centers and 7 criteria were determined by brainstorming method among 18 ski centers and 20 criteria as a result of literature search.

\section{The designated ski resorts are as follows:}

- Uludağ Ski Center (Bursa)

- Kartalkaya Ski Resort (Bolu)

- Erciyes Ski Center (Kayseri)

- Sarıkamıss Ski Center (Kars)

- Palandoken Ski Center (Erzurum) 
- Ilgaz Ski Resort (Kastamonu).

The criteria are as follows:

- Season length

- Unexplored natural beauty

- Snow quality

- Easy access

- Cost-effective according to alternatives

- Number of days to ski

- Advertising and recommendations.

The aim of this study is to evaluate ski center orientations with Analytic Hierarchy Process technique from the point of view of the customers in the selection of the ski resort. 6 ski centers were evaluated by 7 experts with 7 criteria determined by the brainstorming method. Super Decisions package program was used to make mathematical operations easier in evaluations. As a result of the evaluation, the most effective criteria were advertisements and recommendations, while the least effective criterion was seasonal length. Uludağ Ski Center is the most preferred alternative among the determined alternatives.

The Analytic Hierarchy Process (AHP) was created by Myers and Albert in 1968 and later developed by Thomas Lorie Saaty and used in Multiple Qualitative Decision Making problems. In decision-making, taking into account the judgments of human rather than pure information can increase the effectiveness of the decision. Because each person's different approach to events leads to the formation of different criteria and different evaluations for the options. AHP technique does not lead individuals to a certain decision by inserting them into a mold. Instead it allows you to decide on your own initiative. The AHP technique allows decision-makers to reach the solution path in different ways by diversifying the preexisting experience, prediction, intuition, and information they use. It thus simplifies complex solutions by allowing the decision to make both objective and subjective evaluations.

AHP technique is defined as a method which allows the comparison of qualitative and quantitative variables, which allows ranking these variables, which contain many variables and can be used to solve complex problems. It is used to compare the criteria and sub-criteria and determine their superiority and determine the best alternative. The fact that the method is simple and straightforward makes it easier to use in enterprises. The definition of AHP is hidden in sequential Analytical Hierarchy (AH) and Process (P) words and these words guide the most general definition of AHP.

AHP method; In the presence of many alternatives and criteria, it is the simplification of the decision-making process by evaluating the possible paired comparisons and taking the value in the $0-1$ range of alternatives after a number of operations, digitizing them to a total of 1 and reducing the decision to one size. Hierarchy "is defined as, step, degree order, stage order. In AHP method, formatting the problem in an order is the beginning of an easy analysis, while the Turkish equivalent of Process in is a process. That is, the process during which events and facts are sorted in an order. As in the other methods of the AHP method, the decision maker aims to make a decision by saving the process in a certain order after certain steps.

A hierarchical structure was established with the objectives, criteria and alternatives connected with each other. Hierarchical structure provides a better perception of the problem and at the top, the aim is then the criteria and at the bottom, the hierarchical structure has been established by stepping up the alternatives. Afterwards, the data created as a result of the questionnaires for the double comparison matrix will be entered. The data obtained from the surveys will be converted into matrices and used for analysis. Priorities matrix, eigenvector and consistency ratios are calculated for the items in the hierarchy. The calculations were made with the Super Decisions program. Super Decisions is a program that is used in the analysis of AHP and ANP techniques in multi-criteria decision making and is supported by Saaty. In order to solve the problem, the aim, criterion and alternative inputs are made to the program and associations are made. The hierarchical structure draft created in the Super Decisions program has been created below. The aim, criteria and alternatives are linked to each other and to define individual relationships. 
There are multiple criteria for choosing ski centers. To decide which ski resorts is more suitable according to criteria such as season length, unexplored natural beauties, snow quality, ease of transportation, being affordable according to alternatives and number of days that can be skied, it will be appropriate to choose according to the scores obtained by Analytical Hierarchical Process (AHP) method was concluded. 